\title{
SPIAS: Evolutionary approach for Space Science Education Development in Africa
}

\author{
Muhammad ALKALI ${ }^{1}$, Celina Gana ${ }^{2}$, Danlami Idrisu ${ }^{3}$, Mengu Cho ${ }^{1}$ \\ 1) Laboratory of Spacecraft Environment Interaction Engineering, Integrated Systems Engineering, \\ Graduate School of Engineering, Kyushu Institute of Technology, Japan \\ 2) Department of Science Education, Federal University of Technology Minna,Nigeria \\ 3) Department of Computer Science, Niger state College of Education Minna, Nigeria
}

\begin{abstract}
Most students in learning institutions in Africa have little or no knowledge or education on space sciences and technology. On the other hand strong space science researches are hindered due to a lot of factors such as insufficient funding and lessened political will.

Only few educational institutions in Africa are solely involved in projects related to satellite activity that will widen the horizon or ignite students' interest on space sciences from scratch. There are no strong facilities in these endeavours in most of the countries`secondary or tertiary institution. This is really a setback and a clear indication of backwardness in space education in the school system.

Space Science Project Initiative for African Schools (SPIAS) is a good strategy for the development of space education from the scratch in countries that are lagging behind in space Education.
\end{abstract}

Keywords: SPIAS, SSEF, Space Science, KYUTECH, CANSAT

\section{Introduction}

Investment in Education has not been impressive in some countries. Funding in areas of infrastructure, research, professional development and welfare of the academics should not be neglected. A sound educational system in all fields will contribute to the prosperity of a country and its citizenry socially, economically, culturally and globally. A state with solid foundation in space sciences is a focused and wealthy nation.

To position these countries to having sound educational foundation in space sciences and Technology there is need for an evolutionary approach that will catalyze the process in attaining this feat.

Space science education must provide both the required professionals in this field of endeavors and streams of ideas and conducive environment. The benefits of space science education must be tapped through a synergy that re-invigorate and re-orientate the perception of the people on the gains or worthiness of this programme.

Space science and technology education must provide the people a reason to embrace it through innovations and knowledge. Adaptive changes and applications must metamorphose space science knowledge into visible dividends to Africans and the world at large through internal, regional and global collaborations.

The cornerstone for the development of this initiative is the political will and full embraces of the people through a legislation that empowers its operability on the basis that the inputs and outputs of these activities are in tandem with peaceful applications of space sciences.

This scheme is targeted at the governments since they are saddled with the largest crunch of responsibility for education. The partnership or participation of Private sector, UNESCO, UNOOSA, KYUTECH, and other collaborators are highly envisaged.

The strategy for this initiative is composed of five key, interwoven elements that are built on a solid foundation for Space Science \& Technology Development:

> Space Education: This entails taught subjects and courses offered in schools and informal space education approach to enrich the participation of the young stakeholders;

$>$ Space Science Enlightenment: to be up to date and contributory with current advances in space sciences and technologies;

$>$ Responsive adjustment to the needs \& applications: to encourage innovative applications of the acquired space knowledge.

$>$ Collaboration: Both internal and external to be imbibed in.

$>$ Co-ordination: An organized set up to control and monitor the scheme.

There is the need to quickly start working in this direction to get a solid foundation in space science education at all levels.

By applying strategy 3R (Re-orientation, Reconstruction and Regulation) whether in short, medium or long 
term scale:

\section{Re-Orientation}

$>$ Enlightenment of the society and the young ones especially on the need for space education by government through a dedicated agency or parastatal.

> Re-furbishing and provision of facilities and entrenching sound curriculum for space science subjects and taught courses or augmentation of existing physics departments to accommodate space sciences and also outreach activities such as CANSAT competitions, space science symposium, Satellite projects, etc.;

$>$ Funding / collaboration for research and development.

\section{Re-Construction}

$>$ Space Science Education must be included in the priority list of government support; by entrenching it with the befitting quality;

$>$ Enlightenment to popularize the gains of space studies and applications in our communities;

\section{Regulation}

$>$ A dedicated parastatal or office to be established to regulate and roll-on the SPIAS programme. The dedicated establishment to be referred as Space Science Education Development Fund (SSEDF).

$>$ To ensure outputs are beneficial to the people;

$>$ ensure countries' active participation and contribution in the space science knowledge tank ;

$>$ To provide first class facilities and co-ordination of all the space educational activities.

\subsection{SPACE PROJECT INITIATIVE FOR AFRICAN SCHOOLS (SPIAS)}

The space Project Initiative for African Schools (SPIAS) has four major components which includes space Education, Space enlightenment, Collaborations and responsive adjustment to the needs \& applications. SPIAS activities shall be co-ordinated by a proposed parastatal to be called Space Science Education Development Fund (SSEDF) with full mandate.

The SSEF mandates shall include some SPIAS activities which includes and not limited to: Space Science Symposium; Space Science Vacation which shall include space retreats, excursions and Cansat Missions; Demonstration Satellite (DemoSat) projects;

SPIAS is a space programme initiative that will be most suitable to be under the supervision of Federal Ministry of Education and the participating institutions (Civil universities, Polytechnics and Colleges of Education) so as to boost space research activities in educational system and also to provide space science curricular studies to be nurtured to maturity and accreditation by the responsible regulating bodies.

SSEDF should be well funded to be able to implement Space Science Vacation which shall include space retreats, excursions and Cansat Missions; Demonstration Satellite (DemoSat) projects.

\subsubsection{SPACE EDUCATION}

It is a common knowledge that education is wealth. There is the dire need to create a big slot in African educational system with the objective of accommodating the development of space science education in all ramifications and strata ; to increase the expertise or know how in space science ;also increase the workforce in this endeavor mainly groomed locally. And to increase hands on skills this is a paradigm shift from the traditional learning system that is theory based and is usually filled with lessened or partial comprehension of the subject.

\section{The Approach}

$>$ Overhauling of the syllabus and curriculum to follow the trend of current development in space science from secondary to tertiary schools.

$>$ Practical based learning (PBL) should be inculcated in schools.

$>$ The tomorrow needs of the students should be emphasized in so doing; fully baked graduates that are equal to their peers in already established societies should be produced after passing through space education.

$>$ There should be partnership with space related institutions in research/ internship opportunities for the students.

$>$ The teachers should undergo professional development to be able to impact on the students. Expertise can be obtained by collaborating in this direction with high rated institution such as Kyushu Institution of Technology (KYUTECH),IIT,MIT,University of surrey,etc

$>$ Exchange programmes with high rated institution such as Kyushu Institution of Technology (KYUTECH) should be encouraged.

$>$ Accreditation must be highly ethical not political.

$>$ There should be laboratories and scientific facilities to broaden the students understanding.

$>$ Government support in funding should be coordinated through dedicated grants support from Space Science 
Education Development Fund (SSEDF).

\subsubsection{SPACE SCIENCE ENLIGHTENMENT}

The individual country must be up to date with current advances in space sciences and technologies. The objective which includes: understanding astronomy, space physical sciences, technologies and space systems ; create area of research in this fields that is highly standardized and outstanding; encourage collaborative research and also ensure outcomes in this regard from these countries are credible and sorted for.

\section{Approach}

$>$ There should be at least $15 \%$ of government educational budgets in schools dedicated to Space science related researches or activities in schools.

$>$ Building of infrastructures/facilities for spaces science activities to lay down the pre-requisite foundations.

$>$ There should research centers for space sciences jointly owned by schools and stakeholders.

$>$ The experience / and Knowledge of existing professionals in the field should be highly tapped.

$>$ Know how technology courses/ training should be provided for the teachers.

$>$ Research collaboration in these endeavors should be encouraged.

\subsubsection{RESPONSIVE ADJUSTMENT TO THE NEEDS \& APPLICATIONS.}

The aim here is to see innovations and ideas in space sciences and technologies spring into visible products and services, e.g. activities at university of Surrey with Surrey space Centre/ Surrey Satellite Technology Limited and KYUTECH's LASIENE/SVBL.

\section{Approach}

The activities of SPIAS programme should include

$>$ Participation of private sectors and establishment of spin-off companies related to space science and technologies by schools or students.

$>$ Establishment of SSEDF to co-ordinate all this activities as the government regulating /implementing agency.

$>$ Investment promotion in space ideas related applications by established companies internal or external.

$>$ To provide infrastructures for nanosatellite satellite ground testing facilities at the Federal universities of Technology in the country.

$>$ And high standards laboratory for astronomies in some selected conventional universities strategically stationed to increase access opportunities.

\subsubsection{COLLABORATION}

Space studies should be strategically implemented with a strong network at regional and international levels to boost the country's standing in the field. The aim here is to encourage collaboration between African schools and other foreign institutions and to widen its regional and global participation in space research.

\section{Approach}

$>$ Memoranda of understanding between SSEDF/African schools and some established institutions (such as KYUTECH) in this endeavor to tap from their experience and eventually share research interest and challenges in order to:

$\circ$ Hasten the delivery of capacity and know how transfer

- To provide infrastructure and related facilities \{ such as astronomy laboratories, Assembly integration and testing(AIT) facilities, Concurrent Engineering Facilities, etc $\}$

- To be up to date with latest development in space science at the international level.

- To encourage ventures between SSEDF and international institutions.

- space weather monitoring program :Development of inexpensive space weather monitors that students can install and use at local high schools.

$>$ Students or schools network should be encouraged for research or business in space related product and services.

\subsubsection{SPACE SCIENCE EDUCATION DEVELOPMENT FUND (SSEDF)}

There shall be Space science education fund as an intervention unit fully legislated with mandate of managing, and disbursing and monitoring space education tax fund to the public schools.

To enable SSEDF achieve the above objectives, the proposed SSEDF must be empowered to administer and disburse funds to the schools for the provision and maintenance of the followings: 
$>$ Physical infrastructure and facilities for teaching and learning of space science

$>$ Research and publication

$>$ Retreats

$>$ Instructional material and tools for space science and technology education

$>$ Training and development of institutional staffs on space science and application related courses

$>$ Support innovations and practical based learning.

Also to create avenue for international collaborations between schools for development of space science studies, innovations and applications.

\subsubsection{SSEDF MAJOR PROJECTS}

The major projects of SSEF shall include DemoSat series (starting with DemoSat1), Astronomical laboratories, Satellite Ground testing Facilities, etc

\subsection{The Risks}

\section{Risk Management Of SPIAS}

Establishment of SSEDF

Political will on space education is minimal

$>$ Space enthusiasm is low

$>$ Existing space related parastatals feel encroachment of their mandates

$>$ Enactment of the policy for the establishment of SSEF entails a lot of lobbying

$>$ Usurping or /and reduction of the proposed mandates for SSEF

$>$ Having the appropriate professionals in running the schemes

$>$ Provision of Funding/budget

$>$ The capacity and readiness of the teachers at inception.

Limitation in the school commitments

$>$ Magnitude of the restructuring

\subsection{RISK SCORING}

The risk matrix below in table 1 will be used based on the risk scoring

Table 1: Risk matrix

\begin{tabular}{|l|l|l|l|l|}
\hline \multirow{4}{*}{ Impact } & High(H) & HL & HM & HH \\
\cline { 2 - 5 } & Medium(M) & ML & MM & MH \\
\cline { 2 - 5 } & Low(L) & LL & LM & LH \\
\cline { 2 - 5 } & & Low(L) & Medium(M) & High(H) \\
\cline { 2 - 5 } & \multicolumn{2}{|c|}{ Probability } \\
\hline
\end{tabular}

Probability definition

$>$ High $(\mathrm{H})$ : probability of occurrence greater $70 \%$

$>$ Medium(M): probability of occurrence between $30 \%$ to $70 \%$

Low(L): probability of occurrence less than $30 \%$

Impact Definition

$>\operatorname{High}(\mathrm{H})$ : Risk that has the potential to greatly impact project performance

$>$ Medium(M): Risk that has the potential to slightly impact project success

$>$ Low $(\mathrm{L})$ : Risk that has relatively little impact on project success

Risks that are on HL, MM, HH, HM, HH and MH will need risk mitigation and contingency planning. 
Table 2: Risk management register

\begin{tabular}{|c|c|c|c|c|}
\hline Risk & Responsibility & Probability & Impact & Mitigation \\
\hline Establishment of SSEDF & $\begin{array}{ll}> & \text { Government } \\
> & \text { Policy makers } \\
& \text { Educationists } \\
> & \text { Others }\end{array}$ & $\mathrm{L}$ & $\mathrm{L}$ & $\begin{array}{ll}> & \text { Legislation } \\
> & \text { Lobby } \\
> & \text { Idea presentation }\end{array}$ \\
\hline Lack of Political will & $\begin{array}{ll}> & \text { The people } \\
> & \text { Government } \\
> & \text { The schools }\end{array}$ & $\mathrm{M}$ & $\mathrm{L}$ & $\begin{array}{ll}> & \text { Enlightenment } \\
> & \text { Lobby }\end{array}$ \\
\hline Low Enthusiasm & The people & $\mathrm{M}$ & $\mathrm{L}$ & Awareness campaign \\
\hline $\begin{array}{l}\text { Opposition from existing } \\
\text { parastatals }\end{array}$ & $\begin{array}{l}>\quad \begin{array}{l}\text { Space Agencies } \\
\text { Education } \\
\text { agencies }\end{array} \\
\text { agen }\end{array}$ & $\mathrm{H}$ & $\mathrm{H}$ & $\begin{array}{ll}> & \text { Legislation } \\
> & \text { Clear cut mandate } \\
> & \text { Transfer mandate }\end{array}$ \\
\hline Enactment of law issues & $\begin{array}{ll}>\quad \text { National } \\
\text { Assembly } \\
>\quad \text { The Federal } \\
\text { executive }\end{array}$ & $\mathrm{L}$ & $\mathrm{L}$ & $\begin{array}{ll}> & \text { Legislation } \\
> & \text { Lobbying }\end{array}$ \\
\hline Funds related issues & 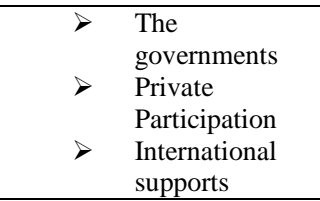 & $\mathrm{M}$ & $\mathrm{M}$ & $\begin{array}{l}\text { Remittance and allocation } \\
\text { legistaltion. }\end{array}$ \\
\hline Teachers development & $\begin{array}{ll}> & \begin{array}{l}\text { School } \\
\text { administrations }\end{array} \\
> & \begin{array}{l}\text { Education } \\
\text { ministries }\end{array} \\
> & \text { Teacher } \\
> & \text { SSEDF }\end{array}$ & $\mathrm{M}$ & $\mathrm{M}$ & 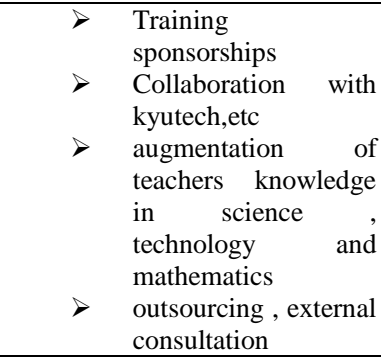 \\
\hline School commitments & $>$ Schools & $\mathrm{M}$ & $\mathrm{M}$ & $\begin{array}{l}\text { Accreditation as yard } \\
\text { stick for funding for } \\
\text { long term. } \\
>\quad \text { Score card }\end{array}$ \\
\hline Magnitude of the task & $>\quad$ Government & $\mathrm{H}$ & $\mathrm{H}$ & $\begin{array}{ll}> & \text { Legislation } \\
> & \text { Funding/Budget } \\
> & \text { External consultation } \\
> & \text { Outsourcing }\end{array}$ \\
\hline
\end{tabular}

\subsection{MONITOR AND CONTROL STRATEGY FOR SPIAS SCHEME}

In other to achieve the desired goal of establishing SPIAS programme; a monitor and control strategy is used with provision of two options or alternative plans for the successful implementation of the scheme. Plan A is the successful implementation of the proposal with establishment of a coordinating agency, SSEDF while Plan B is implementation of the SPIAS scheme through distributing or assigning the proposed mandates to existing structure(s) without need for the establishment of SSEDF. The monitor and control strategy flow chart is shown in figure 1.

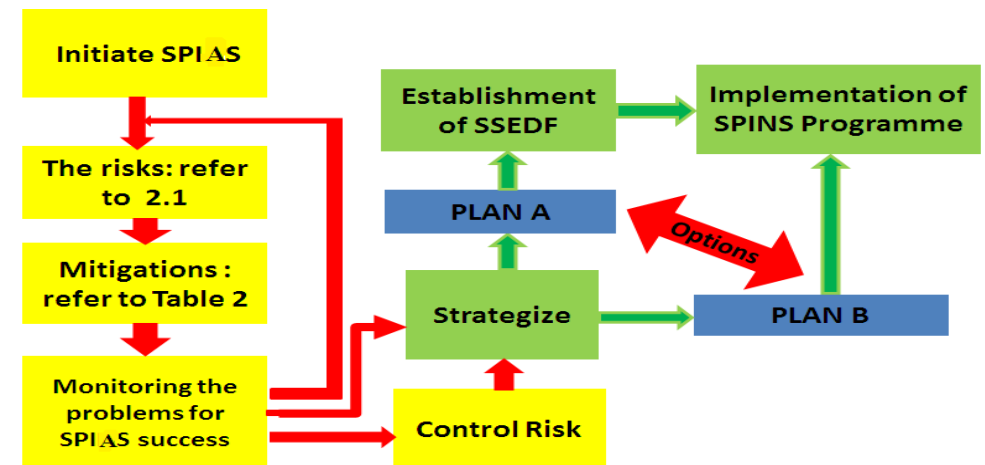

Figure1. Flow chart of Monitor and control for SPIAS Implementation 


\section{Conclusions}

The space project initiative in African schools is meant to open window for space education from the scratch by so doing laying a solid foundation for space education in these countrries.

The strategy for this initiative is composed of five key, interwoven elements that are built on a solid

Space Education, Space enlightenment, Collaborations and responsive adjustment to the needs \& applications.

Also to achieve the desired goal there shall be need for establishment of Space Science Education Development Fund the nucleus for the coordination of these activities such as CANSAT, space symposium, DemoSat Projects.

\section{Reference}

[1]. http://www.jiscinfonet.ac.uk/infokits/risk-management/identifying-risk/cause-and-effect/

[2]. http://www.acoa-apeca.gc.ca/eng/Accountability/AuditsAndEvaluations/Pages/Integrated-risk-management-process-flowchart.aspx

[3]. http://bch.cbd.int/onlineconferences/flowchart_ra.shtml

[4]. http://en.wikipedia.org/wiki/Risk_management

[5]. 5.Oluwaseun,O.T. Space Science Education in high school,ICESA Journal of Solid earth and space physics research Vol.3 No.1, 2006

[6]. Proposal document for Space Project Initiatives in Nigerian schools 